\title{
Focused Review: Agmatine in fermented foods
}

\author{
Fernanda Galgano*, Marisa Caruso, Nicola Condelli and Fabio Favati
}

Department of Biology, Biotechnology and Defense Agro-Forestry, University of Basilicata, Potenza, Italy

\section{Edited by:}

Giovanna Suzzi, Università degli Studi

di Teramo, Italy

Reviewed by:

Giovanna Suzzi, Università degli Studi di Teramo, Italy

Maret Du Toit, Stellenbosch

University, South Africa

*Correspondence:

Fernanda Galgano, Department of Biology, Biotechnology and Defense Agro-Forestry, University of Basilicata, Viale dell'Ateneo Lucano 10, 85100 Potenza, Italy.

e-mail: fernanda.galgano@unibas.it
Polyamines (PAs) are ubiquitous substances considered to be bioregulators of numerous cell functions; they take part in cell growth, division, and differentiation. These biogenic amines are also involved in tissue repair and in intracellular signaling; in fact, because of their polycationic character, they interact to a large extent with membrane phospholipids and may play an important role in the regulation of membrane-linked enzymes. The intracellular polyamine content derives from the simultaneous regulation of the synthesis, catabolism, uptake, and elimination of the polyamines; furthermore, PAs are present in all cell types at different concentrations, but the highest levels are found in rapid-turnover tissues. In addition to spermidine, spermine, and putrescine, also agmatine (AGM), deriving from arginine and identified in mammals in the 1990s, is a polyamine and several studies have reported its potentially positive role in the production of secretagogues, and in neuronal, vascular, metabolic, and therapeutic functions. Because of the low arginine decarboxylase (ADC) activity in mammalians, the amounts of AGM found in their tissues can be only minimally ascribed to an endogenous de novo synthesis by ADC, while a substantial quantity of AGM may be of dietary origin. Several food products contain only small amounts of polyamines, while higher concentrations can be found in fermented foods. PAs could also be considered as indicators of freshness in fish and meat products; as these moieties are produced during food storage, it would seem to confirm the main role of microorganisms in their synthesis. In particular, high levels of AGM are present in alcoholic beverages, such as wine, beer, sake, which would seem to confirm the role of yeasts in AGM production. Although many biological functions have been attributed to polyamines, high levels of these compounds in foodstuffs can have toxicological effects; however, no safe level for the intake of polyamines in a diet has yet been established. In this paper the presence of AGM in different foodstuffs is discussed, also taking into account the various factors affecting its presence and concentration.

Keywords: agmatine, biogenic amines, fermented foods, foodstuffs, polyamines

\section{INTRODUCTION}

Biogenic amines (BAs) are ubiquitous substances occurring in every living cell. They play different roles in cellular metabolism: in particular, polyamines (PAs), such as agmatine (AGM), putrescine (PUT), spermine (SPM), and spermidine (SPD) are considered to be bioregulators of numerous cell functions, being involved in the process of cell growth, division, and differentiation (Galgano et al., 2003). These BAs are also involved in tissue repair and in intracellular signaling; in fact, because of their polycationic character, they interact to a large extent with membrane phospholipids and may play an important role in the regulation of membranelinked enzymes. The intracellular polyamine content derives from the simultaneous regulation of the synthesis, catabolism, uptake, and elimination of the polyamines; furthermore, PAs are present in all cell types at different concentrations, but the highest levels are found in rapid-turnover tissues (Moinard et al., 2005). In mammals their diet also provides a daily supply of PAs and the distribution of the different PAs varies according to the food type. The highest amounts are present in fermented foods and beverages, especially in protein-rich foods, e.g., fish and fish products, meat and meat products, eggs, cheeses, fermented vegetables, fruits, nuts, chocolate, soybean products, and wine (Silla Santos, 1996). Moreover, also processing and additives can influence BA formation in foods: for example, BAs are heat stable compounds and their level is not significantly reduced by high temperature treatment (Naila et al., 2010).

Biogenic amines in foods are generated either as the result of endogenous amino acid decarboxylase activity in raw food materials or by the growth of decarboxylase-positive microorganisms under conditions favorable to enzyme activity (Halász et al., 1999a). As the microbial spoilage of food may be accompanied by the increased production of decarboxylases, the presence of BAs might serve as a useful indicator of food spoilage (Silla Santos, 1996).

Although many biological functions have been attributed to PAs, high levels of these compounds in foodstuffs can have toxicological effects. In fact, even if individually they are not considered toxic, PAs can enhance the effects of histamine (HIS) and tyramine (TYR) by interacting with the aminooxidases and interfering with detoxifying mechanisms. Similarly, other compounds, like alcohol and acetaldehyde, can enhance the toxic potential of BAs, since they promote the transportation of these moieties through the 
intestinal wall. For these reasons, it is difficult to establish the safety threshold of BAs in a given product, because their toxicity does not depend merely on their presence (type and level), but also on individual detoxification mechanisms and on the occurrence of other compounds affecting their activity (EFSA Panel on Biological Hazards (BIOHAZ), 2011; Ruiz-Capillas and Jiménez-Colmenero, 2004).

\section{ORIGIN OF AGMATINE}

The presence of AGM in plants, bacteria, and invertebrates has been known for a long time, but its occurrence in mammals was reported for the first time only in the 1990s and since then growing attention has been focused on this polyamine (Moinard et al., 2005).

AGM is produced from L-arginine by arginine decarboxylase (ADC) and is a PUT precursor, one of the main BAs associated with microbial food spoilage. PUT can originate from arginine via ornithine decarboxylase, or another pathway is by AGM deamination involving three enzymes (AGM deiminase, PUT carbamoyltransferase, and carbamate). This pathway has been demonstrated only in a few microorganisms, such as Pseudomonas aeruginosa PAO1, Enterococcus faecalis ATCC11700, Bacillus cereus ATCC14579, and Lactobacillus hilgardii $\mathrm{X}_{1} \mathrm{~B}$ (Arena and Manca de Nadra, 2001; EFSA Panel on Biological Hazards (BIOHAZ), 2011; Landete et al., 2008). In particular, the amino-biogenic activity of the latter microorganism has been widely demonstrated, especially with regards to the production of AGM and PUT at high concentrations (EFSA Panel on Biological Hazards (BIOHAZ), 2011; Landete et al., 2008).

The presence of pyridoxal, $\mathrm{Mg}^{2+}$, and $\mathrm{Mn}^{2+}$ can enhance ADC activity as well as that of other amino decarboxylases, but agmatine deiminase does not seem to be affected by the presence of these cofactors; conversely, arginine, glucose, and fructose have been shown to exert an inhibitory effect on AGM deamination, whereas high levels of AGM can enhance the production of PUT (Arena and Manca de Nadra, 2001; EFSA Panel on Biological Hazards (BIOHAZ), 2011; Landete et al., 2008). Landete et al. (2008) have reported a positive correlation between the presence of succinate, SPM and SPD, and PUT production in $P$. aeruginosa PAO1. Conversely, in the case of E. faecalis ATCC11700, B. cereus ATCC14579, and L. hilgardii $\mathrm{X}_{1} \mathrm{~B}$ succinate did not have any effect, while SPD and SPM always contributed to the reduction of AGM deamination.

The ability of bacteria to produce BAs is widely documented, whereas there are few reports regarding the formation of BAs by yeasts, even if considerable quantities of AGM and other BAs have been found in wines and other alcoholic beverages (IzquierdoPulido et al., 1996; Glória et al., 1998; Galgano et al., 2003, 2011). Caruso et al. (2002) have reported the ability of Saccharomyces cerevisiae to produce ethanolamine and AGM in inoculated grape must; also other yeast strains isolated from grapes and wines, belonging to the species Candida stellata, Kloeckera apiculata, Metschnikowia pulcherrima, and Brettanomyces bruxellensis, are thought to be capable of producing AGM. In Photobacterium phosphoreum the presence of AGM and PUT has been reported to influence the occurrence of histamine (HIS), consequently inhibiting histidine decarboxylase activity (Karovicová and Kohajdová, 2005).

\section{ROLE OF AGMATINE}

Moinard et al. (2005) have reported that AGM concentrations in the brain have been found to be comparable to that of typical neurotransmitters, thus suggesting that AGM might be a neurotransmitter.

A variety of effects have been demonstrated in response to AGM in vivo and in vitro, but the biological significance of these effects is still under debate, because the concentrations at which the effects were induced were much higher than those present in blood and tissues (Molderings et al., 2002). However, AGM is known to have secretagogue properties, such as the modulation of insulin release and glucose metabolism, the stimulation of adrenaline, and noradrenaline secretion. AGM antagonizes some hyperalgesic states and enhances the dose-related analgesic effect of morphine (Moinard et al., 2005; Wade et al., 2008).

AGM appears to influence appetite regulation. The administration of a high dose of AGM to satiated rats triggered an increase in their caloric intake and their carbohydrate preferences, whereas AGM does not modulate caloric intake in hungry rats (Prasad and Prasad, 1996). AGM also plays an important role in polyamines homeostasis: by inhibiting ornithine decarboxylase, AGM inhibits smooth muscle proliferation (Moinard et al., 2005).

AGM is recognized as an inhibitor of nitric oxide synthase, an enzyme that, starting from arginine, catalyzes the production of nitric oxide (NO), an intercellular messenger implicated in the regulation of various physiological functions in central neurotransmission. It has been suggested that NO may be involved in the mechanism of anxiety, therefore NO inhibitors, such as AGM, may be a potential tool for the treatment of anxiety (Uzbay and Lal, 2002), even though Krass et al. (2008) failed to demonstrate the reported antidepressant and anxiolytic-like activity of AGM.

However, it is highly probable that AGM will play a role in the therapeutic treatment of a number of different diseases. In the treatment of cancer, it has been established that AGM has a antiproliferative effect due to its suppression of polyamine synthesis and cellular polyamine uptake through the induction of antizyme (Agostinelli et al., 2010).

It has also been suggested that AGM could play an important role in the control of ureagenesis, representing a significant contribution to the therapeutic removal of waste toxic nitrogen from the body. Moreover, AGM could be useful in the treatment of sepsis, because its administration to endotoxemic rats has been shown to prevent the decrease in blood pressure and renal function usually associated with sepsis (Moinard et al., 2005).

AGM is also able to protect brain mitochondria against the drop in energy capacity by the $\mathrm{Ca}^{2+}$-dependant induction of permeability transition in rat brain mitochondria (Battaglia et al., 2010). Furthermore, AGM may also be considered as a regulator of mitochondria cell death. In addition, by increasing the expression of antizyme, a protein that inhibits polyamine biosynthesis and transport, AGM exhibits a regulatory effect on cell proliferation (Agostinelli et al., 2010).

The high content of AGM in the lumen of the gastrointestinal tract may also originate from the bacteria of the physiological gut microflora, as well as from pathogens such as Helicobacter pylori.

After oral administration of radiolabeled AGM to rats in vivo, radioactivity was retrieved in all organs investigated, as well as in blood and urine indicating that AGM is absorbed from the 
stomach and the gut by means of an energy-dependent transport mechanism and distributed to the organs via the blood stream. Moreover, the accumulation of radioactivity in organs and distal gut luminal content decreases with the administration of increasing doses of PUT (Molderings et al., 2002).

Because of the low ADC activity in mammalians, only a fraction of AGM in the tissues of the organism can be due to endogenous de novo synthesis by $\mathrm{ADC}$, while a substantial portion can be of dietary origin (Molderings et al., 2002).

\section{AGMATINE IN FOODSTUFFS}

Several food items contain only small amounts of PAs, such as AGM, while higher concentrations can be found in fermented foods. PAs can also be considered as indicators of freshness in fish and meat products, as they are produced during food storage, thus confirming the main role of microorganisms in their synthesis. In particular, AGM is present at high levels in alcoholic beverages, such as wine, beer, and especially in sake $(114 \mathrm{mg} / \mathrm{L}$; Okamoto et al., 1997), while low levels have been found in fermented non-alcoholic beverages, such as Turkish shalgam (Özdestan and Üren, 2010a). This fact could confirm the role of yeasts in AGM production.

In Table $\mathbf{1}$ is summarized the AGM mean content in several foodstuffs.

WINE

The concentration of BAs in wine has been reported to range from a few $\mathrm{mg} / \mathrm{L}$ to about $50 \mathrm{mg} / \mathrm{L}$. The type and concentration of

Table 1 | Agmatine content in different foodstuffs (ppm).

\begin{tabular}{|c|c|c|c|c|}
\hline Foodstuffs & Mean & Range & $\mathbf{N}\left({ }^{A}\right)$ & References \\
\hline \multicolumn{5}{|l|}{ WINE } \\
\hline Red wines & n.s. & n.d.-22 & 286 & Galgano et al. (2003), Galgano et al. (2009), Galgano et al. (2011) \\
\hline White wines & n.s. & n.d.-6.5 & 103 & Galgano et al. (2003), Galgano et al. (2009) \\
\hline BEER & 12 & $0.5-42$ & 211 & $\begin{array}{l}\text { De Borba and Rohrer (2007), Halász et al. (1999a), Izquierdo-Pulido et al. (1996), Kvasnicka } \\
\text { and Voldrich (2006) }\end{array}$ \\
\hline SAKE & 114 & n.s. & n.s. & Okamoto et al. (1997) \\
\hline \multicolumn{5}{|l|}{ COFFEE } \\
\hline Green coffee & n.d. & n.d. & n.s. & Cirilo et al. (2003) \\
\hline Roasted & n.s. & n.d.-1.2 & n.s. & Cirilo et al. (2003) \\
\hline Instant coffee & 0.4 & $0.4-5.3$ & 68 & Leite da Silveira et al. (2007) \\
\hline \multicolumn{5}{|c|}{ CEREALS AND VEGETABLES } \\
\hline Flour & n.d. & n.d. & 5 & Farkas and Hajós (1998) \\
\hline Bread & 3.3 & n.d. -4.7 & 9 & Farkas and Hajós (1998) \\
\hline Soy sauce & n.d. & n.d. & 4 & Kirschbaum et al. (2000) \\
\hline Soybean paste (Doenjang) & 473 & n.d.-5508 & 23 & Shukla et al. (2010) \\
\hline Miso & 6.1 & n.d. -30 & 5 & Kirschbaum et al. (2000) \\
\hline Sauerkraut brine & 4.3 & $2.2-6.7$ & 6 & Halász et al. (1999a) \\
\hline Fermented cabbage juice & n.d. & n.d. & 5 & Kirschbaum et al. (2000) \\
\hline \multicolumn{5}{|c|}{ FISH AND DERIVED PRODUCTS } \\
\hline Fresh fish & 92 & n.d. -401 & 13 & Baker et al. (2010), Chotimarkorn (2011), Paarup et al. (2002), Ruiz-Capillas and Moral (2004) \\
\hline Fish paste & n.d. & n.d. & 3 & Kirschbaum et al. (2000) \\
\hline Cooked fish paste & 29 & n.d.-161 & 28 & Naila et al. (2011) \\
\hline \multicolumn{5}{|c|}{ MEAT AND MEAT PRODUCTS } \\
\hline Fresh meat & 0.8 & n.d.-3.1 & 22 & $\begin{array}{l}\text { Bover-Cid et al. (2001), Hernández-Jover et al. (1996), Lorenzo et al. (2007), Ruiz-Capillas } \\
\text { and Jiménez-Colmenero (2004) }\end{array}$ \\
\hline Fermented meat & 6.2 & n.d. -43 & 23 & $\begin{array}{l}\text { Bover-Cid et al. (2001), Hernández-Jover et al. (1996), Lorenzo et al. (2007), Ruiz-Capillas } \\
\text { and Jiménez-Colmenero (2004) }\end{array}$ \\
\hline Cooked meat & 5.4 & n.d.-27 & 20 & $\begin{array}{l}\text { Hernández-Jover et al. (1996), Ruiz-Capillas and Jiménez-Colmenero (2004), Ruiz-Capillas } \\
\text { et al. (2007) }\end{array}$ \\
\hline \multicolumn{5}{|l|}{ DAIRY PRODUCTS } \\
\hline Fermented milk (Kefir) & n.d. & n.d. & 10 & Özdestan and Üren (2010b) \\
\hline Ripened cheese & 1.1 & n.d-18 & 69 & Novella-Rodríguez et al. (2002), Vale and Glória (1998) \\
\hline Fresh cheese & 0.1 & n.d.-1.3 & 13 & \\
\hline Grated cheese & 1.2 & n.d.-14 & 12 & Vale and Glória (1998) \\
\hline
\end{tabular}

(A) Number of samples examined.

n.d., Not detected.

n.s., Not specified. 
amines in wines depends on several factors, such as winemaking processes, time and storage conditions, raw material quality, and microbial contamination during winery operations. Moreover, some amines are normal constituents of grapes, and their level may vary with grape variety and degree of ripening, as well as with soil type and composition. Therefore, geographical characterization based on the BA content has also been proposed as a criterion to discriminate several types of wines from different countries or regions (Galgano et al., 2009, 2011). BAs usually investigated in wines are cadaverine (CAD), HIS, 2-phenylethylamine (2-PHE), PUT and tyramine (TYR); AGM, and ethanolamine can be abundant in wines, but they are rarely investigated. Low amounts of $\mathrm{BA}$, as normal constituents of the raw materials, can be released in must from grapes during the winemaking process, and the BA concentration may increase as a consequence of alcoholic fermentation, yeast autolysis, malolactic fermentation, and wine aging, red wines usually having a richer amine content than white wines. Generally PUT and AGM can contribute significantly to the total amine content in alcoholic beverages, while CAD, SPM, and SPD are rare (Galgano et al., 2003, 2009, 2011). In particular, PUT is the most abundant BA in wine, while AGM is the most prevalent in beer (Alberto et al., 2007).

For AGM, the concentration has been reported to vary from not detected to $22 \mathrm{mg} / \mathrm{L}$ in red wines and from not detected to $6.5 \mathrm{mg} / \mathrm{L}$ in white wines, while PUT has been found in red wines at concentrations ranging from 0.6 to $21 \mathrm{mg} / \mathrm{L}$ and from not detected to $9 \mathrm{mg} / \mathrm{L}$ in white wines (Galgano et al., 2009). SPD and SPM originate from PUT, which derives from AGM; the latter is generally recognized as an intermediate in the PUT formation pathway, starting from arginine, the most abundant amino acid in grape. PUT can also derive from decarboxylation of ornithine. However, PUT levels increase during fermentation from must to alcoholic, to malolactic fermentation, thus supporting the hypothesis that the principal biosynthetic pathway for PUT formation is via arginineAGM rather than via ornithine (Galgano et al., 2009). Moreover, arginine, from which AGM derives, is present in must at concentrations higher than those found in the finished wine (Galgano et al., 2009). In addition, wines with a low PUT content have been shown to possess a high level of AGM and total polyphenols and vice versa (Galgano et al., 2011). The phenolic compounds seem to be a natural way of reducing PUT formation in wine, because these moieties can protect the cells against oxidative stress (Alberto et al., 2007; Rodríguez et al., 2009).

\section{BEER}

PAs are natural beer constituents and are present in malt and yeast at higher concentrations then in hops (De Borba and Rohrer, 2007; Sohrabvandi et al., 2012), while TYR, HIS, and CAD are considered to be indicators of microbial contamination during brewing (Izquierdo-Pulido et al., 1996). In several beers AGM is the most abundant amine with concentrations ranging from 0.5 to $42 \mathrm{mg} / \mathrm{L}$ (Izquierdo-Pulido et al., 1996; Kvasnicka and Voldrich, 2006; De Borba and Rohrer, 2007). Barley variety, malting technology, and fermentation conditions can influence the BA content in beer both qualitatively and quantitatively. In particular, during wort processing, significant increases of AGM, and PUT have been observed, together with the decrease of SPD and SPM (Halász et al., 1999a).

\section{COFFEE}

The profile and levels of BAs in green and roasted coffee are different; in particular, the degree of roasting significantly influences the amine profile and levels. AGM has been detected in coffee roasted at a high temperature for a long time. In fact, extensive roasting $\left(12 \mathrm{~min}\right.$ at $\left.300^{\circ} \mathrm{C}\right)$ contributes to AGM formation $(1.2 \mathrm{mg} / \mathrm{kg})$ by decarboxylation of arginine, which is present in green coffee at levels ranging from 2 to $5 \mathrm{~g} / 100 \mathrm{~g}$. Conversely, AGM was not found in American coffee, which was roasted for $6 \mathrm{~min}$ at $300^{\circ} \mathrm{C}$. Furthermore, PUT is the most abundant amine in green coffee $(10 \mathrm{mg} / \mathrm{kg}$ ), while it is not present in roasted coffee (Cirilo et al., 2003). Also the processing of instant coffee can influence both the type and level of BAs; instant coffee contains low levels of AGM $(0.4 \mathrm{mg} / \mathrm{kg})$, while the most abundant BA is serotonin, followed by CAD, TYR, and SPD (Leite da Silveira et al., 2007).

\section{CEREALS AND VEGETABLES}

In cereal foods, in particular in flour and bread samples, PUT is reported to be the most abundant $\mathrm{BA}$, at even higher levels than $40 \mathrm{mg} / \mathrm{kg}$, while AGM has been found only in cereal derivates, in particular in different types of bread samples, at concentrations ranging from 3 to $5 \mathrm{mg} / \mathrm{kg}$ of dry matter (Farkas and Hajós, 1998). AGM is also a natural constituent of the seedlings of the winged bean, while is not found in the common bean nor in soybean (Morris, 2003). Since several varieties of molds, yeasts, and lactic acid bacteria are involved in the fermentation processes occurring in the production of several soybean products, and as the substrate is very rich in proteins, the formation of various amines might be expected during fermentation. Several studies have highlighted that BAs in fermented soybean products are most probably formed by the lactic microflora that remains active during fermentation (Kirschbaum et al., 2000). Among many fermented foods that have been consumed for thousands of years in Asian countries, soy sauce, and miso are the most important, and they are obtained by the fermentation of soybean with or without the addition of rice and wheat (in the case of soy sauce) or rice and barley (in the case of miso), using a mix of molds, yeasts, and lactic acid bacteria. In these products AGM has rarely been detected, whereas PUT is one of the most abundant amines that can be found (Kirschbaum et al., 2000). Conversely, in Doenjang, a traditional Korean soybean paste produced by the fermentation of naturally occurring bacteria and fungi, the presence of AGM was reported, in concentrations ranging from not detected to over $5500 \mathrm{mg} / \mathrm{kg}$ (Shukla et al., 2010).

Recently Özdestan et al. (2011) have investigated the BA content in Kumru, a traditional Turkish fermented cereal food produced from chickpeas. In this case not detectable amounts of AGM were found in the product, while other BAs, such as PUT, CAD, SPD, SPM, and HIS were present in all samples.

Fermentation temperature, salt concentration, and starter selection have a significant effect on BA production in sauerkraut (fermented cabbage). In particular, the AGM level seems to be dependent on the inoculum concentration of Lactobacillus curvatus. In sauerkraut brine, AGM was found to be the prevalent amine, reaching a maximum value of $12 \mathrm{mg} / \mathrm{L}$ (Halász et al., 1999b). Conversely, other authors have reported that lactic fermented cabbage juices do not contain AGM, while PUT, estimated at levels of up 
to $360 \mathrm{mg} / \mathrm{L}$, is the most abundant amine, with assessed levels up to $360 \mathrm{mg} / \mathrm{L}$; Kirschbaum et al., 2000).

\section{FISH AND FISH DERIVED PRODUCTS}

SPM and SPD are usually the main PAs present in fresh tissues, at concentrations of less than $10 \mathrm{mg} / \mathrm{kg}$. Depending on the fish species, the free amino acids present in the tissues, and the exposure conditions to spoilage bacteria, other amines can originate during storage or processing, reaching harmful levels, as reported for HIS in the case of animals belonging to the mackerel and herring families (Clifford and Walker, 1992; Önal, 2007). The existence of a synergic relationship between SPM, SPD, and HIS with potentially negative consequences on health, has been hypothesized (Silla Santos, 1996). Therefore, various indexes have been proposed for fish derived products, such as the "BA index," corresponding to the sum of the HIS, PUT, CAD, and TYR content (Veciana-Nogues et al., 1997), or the "quality index," directly related to the HIS, PUT, and CAD content and inversely related to the amounts of SPM and SPD (Mietz and Karmas, 1997). Moreover, several authors have indicated that AGM may be used as a freshness index, because immediately after catch AGM can not be detected or its level is very low, but then in various fish species the AGM content increases progressively during chilling storage, reaching concentrations of over $300 \mathrm{mg} / \mathrm{kg}$ after 7 days of storage (Yamanaka et al., 1987; Paarup et al., 2002; Baker et al., 2010; Chotimarkorn, 2011). The formation of BAs, commonly related to fish spoilage (HIS, TYR, $\mathrm{CAD}$, and AGM), was found to be significantly higher in the first stage of ripening in ungutted anchovies than in gutted ones. Conversely, no differences have been observed regarding the content of SPM and SPD (Pons-Sanchez-Cascado et al., 2003). In Rihaakuru, a cooked fish paste, the AGM concentration is extremely variable, ranging from not detected to $161 \mathrm{mg} / \mathrm{kg}$ (Naila et al., 2011), whereas in other fermented and non-fermented fish paste, AGM is not detectable (Kirschbaum et al., 2000). Fish storage conditions can help to reduce the processes favoring the formation of BAs. In particular, refrigeration with flaked ice, traditionally applied to fish, significantly reduces AGM and the formation of other BAs compared with refrigeration at the same temperature, but without ice (Chotimarkorn, 2011). Protective atmosphere packaging (PAP) is frequently used to prolong the shelf-life of foodstuffs, and effectively reduces BA concentrations in different fish. In particular, Ruiz-Capillas and Moral (2004) have shown that for tuna a gas mixture containing $60 \% \mathrm{CO}_{2}$ is more effective in reducing these moieties than a gas mixture containing $40 \% \mathrm{CO}_{2}$. This was particularly true in the case of white muscle of tuna, where after 25 days of storage an atmosphere containing $60 \% \mathrm{CO}_{2}$ caused a 10 -fold reduction of the AGM level compared with the control stored in air.

\section{MEAT AND MEAT PRODUCTS}

Biogenic amines can be found in processed meat products as a consequence of microbial activity related to fermentation occurring during processing, or to microbial contamination of poor quality raw meat. Therefore, in cooked meat products (non-fermented) BAs may represent a useful indicator for assessing the hygienic quality of the raw meat utilized for preparing these foodstuffs (Bover-Cid et al., 2001). Furthermore, the nitrosable secondary amines (AGM, SPD, and SPM) can form nitrosamines by reaction with nitrites, chemical agents considered to possess major carcinogenic properties. This is particularly important in some meat products with high polyamine levels and whose production process requires the use of nitrates and nitrites (Ruiz-Capillas and Jiménez-Colmenero, 2004). As with fish, also fresh meat normally contains PAs such as SPM and SPD, the levels of which may vary slightly in fermented and ripened meat products. In fresh meat AGM can be found at levels ranging from not detectable to about $3 \mathrm{mg} / \mathrm{kg}$, while in fermented and ripened meat products the AGM content may range more widely from not detectable to about $43 \mathrm{mg} / \mathrm{kg}$. However, it has been reported that in these products a low formation of PUT can be related to the presence of high levels of AGM, the latter being an intermediate metabolite in the PUT production pathway from arginine. Generally cooked meat products show lower polyamine concentrations than fresh meat (Hernández-Jover et al., 1996; Bover-Cid et al., 2001).

Dry-cured "lacón" is a traditional cured meat product made in Spain, following manufacturing processes very similar to those utilized in the production of dry-cured ham. During the manufacture of dry-cured lacón the content of BA may vary greatly, as is also the case with ham. In addition, higher levels of TRYPT have been found in fresh lacón pieces than in fresh meat, whereas AGM has not been detected. However, AGM was generated during the drying-ripening stage, both with and without additives and the values reached in the final product (around $8 \mathrm{mg} / \mathrm{kg}$ ) were higher than those found in ham (Lorenzo et al., 2007).

The technology applied in meat processing may influence BA production. For example, sugar omission in the production of slightly fermented sausages is not recommended, because it may cause an increase in AGM and the accumulation of other BAs during manufacture and storage (Bover-Cid et al., 2001). Furthermore, different concentrations of BAs have been found in fresh, fermented, and cooked meat products, either treated with high pressure processing (HPP) or under PAP, which were closely related to the type of product and the processing conditions. In general, PAP has a positive effect in reducing BA formation in these products. In commercial meat products treated with HPP, higher BA concentrations, particularly AGM, have been reported compared with non-treated samples. This negative effect of HPP has also been observed in frankfurters, butifarra, cooked ham, and chorizo; for the latter product, it has been observed how commercially available non-treated samples may contain AGM concentrations of about $2 \mathrm{mg} / \mathrm{kg}$, while chorizo treated by HPP may show a 20-fold increase in AGM content (Ruiz-Capillas and Jiménez-Colmenero, 2004; Ruiz-Capillas et al., 2007).

\section{MILK AND DAIRY PRODUCTS}

In milk, as in other fresh foods derived from animals, SPM and SPD are the prevalent PAs, whereas it must be reported that AGM was not detectable (Novella-Rodríguez et al., 2002). Also in industrial kefir, a milk product belonging to the category of mixed lactic acid and ethanol fermented beverages, AGM was not detectable. The estimated BA content in kefir, ranging from 2 to $35 \mathrm{mg} / \mathrm{L}$, is generally lower than that found in other fermented foods. Short fermentation time, the use of starter culture, controlled production conditions such as heating at $90-95^{\circ} \mathrm{C}$ before fermentation 
and a low microbial count in the raw material are the main reasons for the low BA content. Higher BA levels can be expected in artisanal or home-made kefir compared with industrial samples, because of worse hygienic conditions (Özdestan and Üren, 2010b).

Cheeses represent an ideal environment for the production of amines. The factors influencing the formation, accumulation, and type of amines are: the availability of amino acids, the presence of bacteria capable of decarboxylating amino acids, $\mathrm{pH}$, salt concentration, water availability, temperature and duration of ripening and storage, bacterial density, the presence of cofactors, and amine catabolism. The $\mathrm{pH}$ of cheese is appropriate for BA production, generally between 5.0 and 6.5, depending on the age and type of the products. Cheeses are also rich in pyridoxal phosphate, which is required for amino acid decarboxylase activity. Studies have shown that in cheese the concentration of BAs decreases with increased fat content. This phenomenon has been attributed to changes in the water activity, which inhibits the growth of proteolytic bacteria, causing a reduction of free amino acid concentration in the medium (Ruiz-Capillas and Jiménez-Colmenero, 2004). Numerous bacteria, both intentional or adventitious and isolated from cheese, have been reported as BA producers (Vale and Glória, 1998; Novella-Rodríguez et al., 2002). Several outbreaks of HIS poisoning have occurred following the consumption of cheese; also cases of hypertensive crisis and migraine headache have been

\section{REFERENCES}

Agostinelli, E., Marques, M. P. M., Calheiros, R., Gil, F. P. S. C., Tempera, G., Viceconte, N., Battaglia, V., Grancara, S., and Toninello, A. (2010). Polyamines: fundamental characters in chemistry and biology. Amino Acids 38, 393-403.

Alberto, M. R., Arena, M. E., and Manca De Nadra, M. C. (2007). Putrescine production from agmatine by $\mathrm{Lac}$ tobacillus hilgardii: effect of phenolic compounds. Food Control 18, 898-903.

Arena, M. E., and Manca de Nadra, M. C. (2001). Biogenic amine production by Lactobacillus. J. Appl. Microbiol. 90, 158-162.

Baker, J., Yassoralipour, A., Bakar, F. A., and Rahman, R. A. (2010). Biogenic amines changes in barramundi (Lates calcarifer) slices stored at $0^{\circ} \mathrm{C}$ and $4^{\circ} \mathrm{C}$. Food Chem. 119, 467-470.

Battaglia, V., Grancara, S., Satriano, J., Saccoccio, S., Agostinelli, E., and Toninello, A. (2010). AGM prevent the $\mathrm{Ca}_{2}{ }^{+}$-dependant induction of permeability transition in rat brain mitochondria. Amino Acids 38 , 431-437.

Bover-Cid, S., Izquierdo-Pulido, M., and Vidal Carou, M. C. (2001). Changes in biogenic amine and polyamine contents in slightly fermented sausages manufactured with and without sugar. Meat Sci. 57, 215-221.
Caruso, M., Fiore, C., Contursi, M., Salzano, G., Paparella, A., and Romano, P. (2002). Formation of biogenic amines as a criteria for the selection of wine yeasts. World J. Microbiol. Biotechnol. 18, 159-163.

Chotimarkorn, C. (2011). Quality changes of anchovy (Stolephorus heterolobus) under refrigerated storage of different practical industrial methods in Thailand. J. Food Sci. Technol. doi:10.1007/s13197-011-0505-y

Cirilo, M. P. G., Coelho, A. F., Araúio, C. M., Gonçalves, F. R. B., Nogueira, F. D., and Glória, M. B. A. (2003). Profile and levels of bioactive amines in green and roasted coffee. Food Chem. $82,397-402$.

Clifford, M. N., and Walker, R. (1992). The aetiology of scombrotoxicosis. Int. J. Food Sci. Technol. 27, 721-724.

Custódio, F. B., Tavares, E., and Glória, M. B. A. (2007). Extraction of bioactive amines from grated Parmesan cheese using acid, alkaline and organic solvent. J. Food Compost. Anal. 20, 280-288.

De Borba, B. M., and Rohrer, J. S. (2007). Determination of biogenic amines in alcoholic beverages by ion chromatography with suppressed conductivity detection and integrated pulsed amperometric detection. $J$. Chromatogr. 1155, 22-30.

EFSA Panel on Biological Hazards (BIOHAZ). (2011). Scientific opinion on (risk) based control of

observed after the ingestion of cheeses with high levels of TRYPT and 2-PHE. The use of bacteriocin-producing starters can prevent the formation of HIS. Moreover, the addition of microbial isolates that degrade BAs in order to prevent the presence of hazardous levels of amines in the final products has been proposed. Although the type and levels of amines in each kind of cheese may vary considerably, AGM is a polyamine which is rarely present in cheeses (Vale and Glória, 1998; Novella-Rodríguez et al., 2002; Custódio et al., 2007).

\section{CONCLUSION}

PAs are produced in all living organisms and play an important role in cell growth and development, as well in protecting stressed cells. Our diet also provides a daily supply of PAs, and high PA concentrations in food can trigger toxic effects and intensify the toxicological effect of HIS. Moreover, the beneficial effects of the polyamine AGM for human health, in its various functions from neurotransmitter or neuromodulator, to stimulator of insulin release and tumor suppressor agent are well known. As only a limited amount of this amine is produced in mammal cells, food ought to contain a certain quantity of the AGM. However, the appropriate AGM level in different food types is a complex relationship which depends on numerous factors.

biogenic amine formation in fermented foods. EFSA J. 9, 2393.

Farkas, S., and Hajós, G. (1998). Monitoring of biologically amines in cereals and cereals based food products by HPLC. Chromatographia 48 , 37-42.

Galgano, F., Caruso, M., and Favati, F. (2009). "Biogenic amines in wines: a review," in Red Wine and Health, ed. P. O’Byrne (New York: Nova Science Publishers Inc.), 173-203.

Galgano, F., Caruso, M., Favati, F., and Romano, P. (2003). HPLC determination of agmatine and other amines in wine. Int. J. Sci. Wine 37, 237-242.

Galgano, F., Caruso, M., Perretti, G. and Favati, F. (2011). Authentication of Italian red wines on the basis of the polyphenols and biogenic amines. Eur. Food Res. Technol. 232, 889-897.

Glória, M. B., Watson, T., Sarkadi, L. S. and Daeschel, M. A. (1998). A survey on biogenic amines in Oregon Pinot noir and Cabernet Sauvignon wines. Am. J. Enol. Vitic. 49, 279-282.

Halász, A., Baráth, Á., and Holzapfel, W. H. (1999a). The biogenic amine content of beer; the effect of barley, malting and brewing on amine concentration. Eur. Food Res. Technol. 208, 418-426.

Halász, A., Baráth, Á., and Holzapfel, W. H. (1999b). The influence of starter culture selection on sauerkraut fermentation. Eur. Food Res. Technol. 208, 434-438.
Hernández-Jover, T., Izquierdo-Pulido, M., Veciana-Nogués, M., and VidalCarou, M. C. (1996). Ion-pair high-performance liquid chromatographic determination of biogenic amines in meat and meat products. J. Agric. Food Chem. 44, 2710-2715.

Izquierdo-Pulido, M. I., Jover, T. H., Font, A. M., and Vidal-Carou, M. C. (1996). Biogenic amines in European beers. J. Agric. Food Chem. 44, 3159-3163.

Karovicová, J., and Kohajdová, Z. (2005). Biogenic amines in food. Chem. Pap. 59, 70-79.

Kirschbaum, J., Rebscher, K., and Brückner, H. (2000). Liquid chromatographic determination of biogenic amines in fermented foods after derivatization with 3,5-dinitrobenzoyl chloride. J. Chromatogr. A 881, 517-530.

Krass, M., Wegener, G., Vaser, E., and Volke, V. (2008). Antidepressant-like effect of AGM is not mediated by serotonin. Behav. Brain Res. 188, 324-328.

Kvasnicka, F., and Voldrich, M. (2006). Determination of biogenic amines by capillary zone electrophoresis with conductometric detection. J. Chromatogr. A 1103, 145-149.

Landete, J. M., Arena, M. E., Pardo, I., Manca de Nadra, M. C., and Ferrer, S. (2008). Comparative survey of putrescine production from agmatine deamination in different bacteria. Food Microbiol. 25, 882-887. 
Leite da Silveira, T. M. L., Tavares, E., and Glória, M. B. A. (2007). Profile and levels of bioactive amines in instant coffee. J. Food Compost. Anal. 20, 451-457.

Lorenzo, J. M., Martínez, S., Franco, I., and Carballo, J. (2007). Biogenic amines content during the manufacture of dry-cured lacón, a Spanish traditional meat product: effect of some additives. Meat Sci. 77, 287-293.

Mietz, J. L., and Karmas, E. (1997). Chemical quality index of canned tuna as determined by highperformance liquid chromatography. J. Food Sci. 42, 155-158.

Moinard, C., Cynober, L., and de Bandt, J. P. (2005). Polyamines: metabolism and implications in human diseases. Clin. Nutr. 24, 184-197.

Molderings, G. J., Heinen, A., Menzel, S., and Göthert, M. (2002). Exposure of rat isolated stomach and rats in vivo to [14C] agmatine: accumulation in the stomach wall and distribution in various tissues. Fundam. Clin. Pharmacol. 16, 219-225.

Morris, B. (2003). Bio-functional legumes with nutraceutical, pharmaceutical, and industrial uses. Econ. Bot. 57, 254-261.

Naila, A., Flint, S., Fletcher, G., Bremer, P., and Meerdink, G. (2010). Control of biogenic amine in food - existing and emerging approaches. J. Food Sci. 75, R139-R150.

Naila, A., Flint, S., Fletcher, G. C. Bremer, P. J., and Meerdink, G. (2011). Biogenic amines and potential histamine-forming bacteria in Rihaakuru (a cooked fish paste). Food Chem. 128, 479-484.

Novella-Rodríguez, S., Veciana-Nogués, M. T., Roig-Sagués, A. X., TrujilloMesa, A. J., and Vidal-Carou, M. C. (2002). Influence of starter and nonstarter on the formation of biogenic amine in goat cheese during ripening. J. Dairy Sci. 85, 2471-2478.

Okamoto, A., Sugi, E., Koizumi, Y., Yanagida, F., and Udaka, S. (1997). Polyamine content of ordinary foodstuffs and various fermented foods. Biosci. Biotech. Biochem. 61, 1582-1584.

Önal, A. (2007). A review: current analytical methods for the determination of biogenic amines in foods. Food Chem. 103, 1475-1476.

Özdestan, Ö., Alpozen, E., Guven, G., and Üren, A. (2011). Monitoring of biogenic amines in Kumru: a traditional fermented cereal food. Int. J. Food Properties doi:10.1080/10942912.2010.511754

Özdestan, Ö., and Üren, A. (2010a). Biogenic amine content of shalgam (salgam): a traditional lactic acid fermented Turkish beverage. J. Agric. Food Chem. 58, 2602-2608.

Özdestan, Ö., and Üren, A. (2010b). Biogenic amine content of kefir: a fermented dairy product. Eur. Food Res. Technol. 231, 101-107.

Paarup, T., Sanchez, J. A., Moral, A., Christensen, H., Bisgaard, M., and Gram, L. (2002). Sensory, chemi$\mathrm{cal}$ and bacteriological changes during storage of iced squid (Toradopsis eblanae). J. Appl. Microbiol. 92, 941-950.

Pons-Sanchez-Cascado, S., VecianaNogues, M. Y., and Vidal-Carou, M. C. (2003). Effect of delayed gutting on biogenic amine contents during ripening of European anchovies. Eur. Food Res. Technol. 216, 489-483.

Prasad, A., and Prasad, C. (1996). AGM enhances caloric intake and dietary carbohydrate preference in satiated rats. Physiol. Behav. 60, 1187-1189.

Rodríguez, H., Curiel, J. A., Landete, J. A., de las Rivas, B, López de Felipe,
F., Gómez-Cordovés, C., José Miguel Mancheño, J. M., and Muñoz, R. (2009). Food phenolics and lactic acid bacteria. Int. J. Food Microbiol. 132, 79-90.

Ruiz-Capillas, C., Carballo, J., and Jiménez-Colmenero, F. (2007). Consequences of high-pressure processing of vacuum-packaged frankfurters on the formation of polyamines: effect of chilled storage. Food Chem. 104, 202-208.

Ruiz-Capillas, C., and JiménezColmenero, F. (2004). Biogenic amines in meat and meat products. Crit. Rev. Food Sci. Nutr. 44 489-499.

Ruiz-Capillas, C., and Moral, A. (2004). Free amino acids and biogenic amines in red and white muscle of tuna stored in controlled atmosphere. Amino Acids 26, 125-132.

Shukla, S., Park, H. E., Kim, J. K. and Kim, M. (2010). Determination of biogenic amines in Korean traditional fermented soybean paste (Doenjang). Food Chem. Toxicol. 48 1191-1195.

Silla Santos, M. H. (1996). Biogenic amines. Their importance in foods. Int. J. Food Microbiol. 29, 213-231.

Sohrabvandi, S., Mortazavian, A M., and Rezaei, K. (2012). Health-related aspects of beer: a review. Int. J. Food Properties 15, 350-373.

Uzbay, T. I., and Lal, H. (2002). Effects of NG-nitro-L-arginine methyl ester, 7-nitro indazole, and AGM on pentylenetetrazol-induced discriminative stimulus in Long-Evans rats. Prog. Neuropsychopharmacol. Biol. Psychiatry 26, 567-573.

Vale, S., and Glória, M. B. A. (1998). Biogenic amines in Brazilian cheese. Food Chem. 63, 343-348.
Veciana-Nogues, M. T., Marine-Font, A., and Vidal-Carou, M. C. (1997) Biogenic amines as hygienic quality indicators of tuna. Relationships with microbial counts, ATP-related compounds, volatile amines, and organoleptic changes. J. Agric. Food Chem. 45, 2036-2041.

Wade, C., Schuster, D. J., Domingo, K., Kitto, K. F., and Fairbanks, C. A. (2008). Supraspinallyadministrated AGM attenuates the development of oral fentanyl selfadministration. Eur. J. Pharmacol. 587, 135-140.

Yamanaka, H., Shiomi, K., and Kikuchi, T. P. Y. (1987). Agmatine as a potential index for freshness of common squid (Totarodes pacificus). J. Food Sci. 52, 936-938.

Conflict of Interest Statement: The authors declare that the research was conducted in the absence of any commercial or financial relationships that could be construed as a potential conflict of interest.

Received: 07 March 2012; accepted: 15 May 2012; published online: 07 June 2012.

Citation: Galgano F, Caruso $M$, Condelli $N$ and Favati $F$ (2012) Focused Review: Agmatine in fermented foods. Front. Microbio. 3:199. doi: 10.3389/fmicb.2012.00199

This article was submitted to Frontiers in Food Microbiology, a specialty of Frontiers in Microbiology.

Copyright ( 92012 Galgano, Caruso, Condelli and Favati. This is an open-access article distributed under the terms of the Creative Commons Attribution Non Commercial License, which permits noncommercial use, distribution, and reproduction in other forums, provided the original authors and source are credited. 